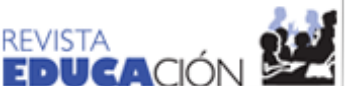

Revista Educación

ISSN: 0379-7082

ISSN: 2215-2644

revedu@gmail.com

Universidad de Costa Rica

Costa Rica

\section{Fenomenología de la responsabilidad por el Otro: un estudio sobre la vocación de la docencia}

\author{
Fernández Guayana, Tany Giselle \\ Fenomenología de la responsabilidad por el Otro: un estudio sobre la vocación de la docencia \\ Revista Educación, vol. 44, núm. 1, 2020 \\ Universidad de Costa Rica, Costa Rica \\ Disponible en: http://www.redalyc.org/articulo.oa?id=44060092039 \\ DOI: https://doi.org/10.15517/revedu.v44i1.39145
}

Esta obra está bajo una Licencia Creative Commons Atribución-NoComercial-SinDerivar 3.0 Internacional. 


\title{
Fenomenología de la responsabilidad por el Otro: un estudio sobre la vocación de la docencia
}

Phenomenology as the Responsibility of the Other: A Study on Teaching Vocation

Tany Giselle Fernández Guayana

Fundación CINDE en alianza con la Universidad de

Manizales, Colombia

tany.fernandezg@gmail.com

iD http://orcid.org/0000-0002-4726-5028

\author{
DOI: https://doi.org/10.15517/revedu.v44i1.39145 \\ Redalyc: http://www.redalyc.org/articulo.oa?id=44060092039
}

Recepción: 01 Octubre 2019

Aprobación: 16 Diciembre 2019

\section{RESUMEN:}

Este artículo presenta los resultados de un estudio fenomenológico cuyo propósito fue comprender y describir los sentidos que las personas docentes le otorgan a su responsabilidad educativa. Participó profesorado que se desempeñaba en los niveles de educación preescolar, básica, media y superior según lo establece la ley colombiana. La investigación se enmarca en un estudio cualitativo con metodología fenomenológica. Se elaboró y se estableció como método la fenomenología de la responsabilidad cuyos existenciales se enmarcan en: la renuncia, la preocupación, la apertura, la donación y la afectación por el Otro, así como la espacialidad, la temporalidad y la materialidad de Max Van Manen. La técnica de recolección de información fue la entrevista fenomenológica. Los resultados evidencian la vivencia de la responsabilidad educativa a partir de un proceso: maestros y maestras inician desprendiéndose de sí mismos lo cual les posibilita abrirse a la presencia desbordante del estudiantado, y, por tanto, brindar una respuesta a la demanda del Otro: una respuesta ética. Como conclusión se establece que la responsabilidad que le otorga el profesorado a su quehacer educativo es una vocación por el Otro. Se recomienda ampliar los criterios de selección del cuerpo docente para futuros estudios, así como aplicar la fenomenología de la responsabilidad en otros agentes educativos.

Palabras ClaVe: Fenomenología, el Otro, Responsabilidad, Vocación educativa, Docente.

\section{Abstract:}

The results of a phenomenological study are presented with the goal of understanding and describing the meaning that teachers attribute to their responsibility as educators. Preschool, Grammar School, Middle School and High School teachers as required by Colombian law, participated in this study. This research was qualitative with a phenomenological methodology of responsibility enshrined in: resignation, concern, openness, giving and affection towards the Other as well as Max Van Manen's space, temporality and materiality. Data gathering techniques included phenomenological interviews. Results reflect that experiencing educational responsibility is based on a process where teachers must become detached and open to the overwhelming presence of students and, thus, respond to the demands of the Other: a response to ethical demands. To conclude, one can state that a teacher's responsibility towards education is a vocation towards the Other. We recommend broadening faculty selection criteria for future studies as well as applying phenomenology of responsibility to other educational agents.

KEYWORDS: Phenomenology, the Other, Responsibility, Educational Vocation, Teacher.

\section{INTRODUCCIÓN}

El ingreso al mundo universitario tanto para el profesorado como para el estudiantado está marcado por dinámicas muy diferenciadas de las prácticas escolares que la preceden; la teoría y la investigación enmarcan buena parte de la vida diaria del personal docente, así como la proyección social y el quehacer académico. En medio de tantos compromisos, llega un momento en el cual es necesario salirse de ese esquema, pues se torna imposible hacerse cargo de otros desempeños que son inmanentes a ese quehacer.

Ejemplo de ello, son las características con las cuales la juventud llega hoy día al aula universitaria. Ellos se ven enfrentados a la soledad, la frustración, las adicciones, el narcisismo, la depresión, el duelo, el apego, 
el individualismo, el desamor, la inestabilidad emocional y el aburrimiento (Gaja, 2016) que los lleva a un sinsentido de la vida que hace de su cotidianeidad una lucha constante. Junto a esto, el abandono permanente de las estructuras de acogida (Duch, 2002) como la familia, han hecho que jóvenes encuentren en sus educadores una figura para ser escuchados, orientados y acompañados en la toma de sus propias decisiones.

En el estudio cualitativo de corte fenomenológico Sentidos de alteridad en los docentes de educación media (Lamprea y Pineda, 2017) se arroja como principal resultado que, el profesorado asume la educación como un encuentro condicionado por la alteridad del Otro, lo cual le permite hacer conciencia del Otro y de su influencia en el desarrollo de su quehacer. Así mismo, en la investigación cualitativa interpretativa $L a$ hospitalidad en profesores memorables universitarios (Porta y Flores, 2017) se llegó a la conclusión que la hospitalidad involucra el orden de la afección, no solo es un hacer, sino también un padecer con el Otro, caracterizando al profesorado en términos sensibles y morales.

Por su parte, en el estudio cualitativo de enfoque hermenéutico Las prácticas pedagógicas en la básica primaria: un espacio para reconocer al Otro (Parra y Vallejo, 2013) se llega a la conclusión de que maestros y maestras están llamados a utilizar el diálogo y el intercambio como un acto pedagógico de otredad, así establecen prácticas humanizantes las cuales partan del Otro y se ejecuten con el Otro. En cuanto a la investigación cualitativa fenomenológica-hermenéutica Sentido de la alteridad en la formación del licenciado en Educación Física (Orrego y Portela, 2009) se encontró que el Otro aparece como una forma de romper el sistema formal académico en tanto conocimiento se comparte y se reconstruye constantemente desde análisis críticos, reflexivos y propositivos, y, por tanto, se reconoce al Otro como totalmente Otro.

Ante esta demanda, surge la necesidad de considerar la educación como un espacio de encuentro donde la "proximidad logra hacerse cargo del Otro" (Lévinas, 2014, p.14). En ese sentido, un educador no solo debe atender a los requisitos institucionales y sociales que le son exigidos, sino que también debe responder a un ejercicio pasional: padecer con el Otro, por quien demanda de su preocupación y responsabilidad (Aguirre y Jaramillo, 2006; Romero y Pérez, 2012). Hoy día las formas pedagógicas invitan a otro lenguaje, a encontrar la voz propia y a acoger la fragilidad del Otro (Jaramillo, 2017).

Las personas educadoras entonces no son transmisoras de verdades, son una voz que ha sido invisibilizada a causa de la burocracia académica y, por tanto, se hace necesario resignificar su rol. Dado lo anterior, se hace imprescindible cuestionarse el sentido de la responsabilidad por el Otro, responsabilidad que, en el quehacer pedagógico, es otorgada de manera inherente pero que suele ser olvidada. A partir de lo anterior la pregunta de investigación que suscita estas reflexiones, es la siguiente: ¿Cuáles son los sentidos que el profesorado le otorga a su responsabilidad educativa?

\section{RefERENTES CONCEPTUALES}

\section{La educación en el Otro}

Referirse a la educación, significa tener en cuenta numerosas posturas y vertientes que han intentado definirla. A pesar de que a lo largo de la historia, de las transformaciones culturales, sociales, políticas, económicas y de las concepciones pedagógicas, ninguna de sus acepciones ha perdido su esencia: la educación es el vehículo por el cual las generaciones transcurren mediante un intercambio responsable entre personas libres que toman decisiones por sí mismas, transformándose y transformando a otros (Casanova, 1991).

La palabra educación proviene de los verbos latinos educare y educere. Educare evoca la acción de crear e instruir, va de adentro hacia afuera. Por su parte educere es el acto de encaminar hacia (Meirieu, 2006), constituye una salida: va de dentro hacia afuera (Bárcena, 2016). Por su parte, John Dewey (citado en Casanova, 1991) manifiesta que la educación es "la suma total de los procesos a través de los cuales una 
comunidad transmite sus fines, con el objetivo de asegurar su propio desarrollo" (p.9). De esta manera la educación se configura en un proceso intencional e integrador.

Educar implica la transmisión de algo que vale la pena (Bárcena, 2005). Es un compromiso que se hace con el Otro, un compromiso con el cambio, con el crecimiento y con la mejora. Un compromiso con la constante formación: el múltiple hacerse del Otro. Es así como la educación,

constituye un acontecimiento de orden ético dentro del cual se encuentra una relación, es decir, la presencia de un Otro que nos trasciende y frente al cual se tiene la obligación de asumir una responsabilidad incondicional más allá de todo contrato posible o reciprocidad (Mèlich, 2014, p.43).

La educación entonces posibilita el encuentro de dos fuerzas: una que busca y otra que guía. Dos personas (docentes-estudiantes) que al entrar en contacto se influyen y transforman para ser cada vez más solidarias, más responsables, más tolerantes; para que sus miembros puedan entrar al mundo de la alfabetización escrita y tecnológica; para transformarlos en sujetos de derecho y borrar las desigualdades sociales, económicas, culturales y lingüísticas; para prevenir conflictos raciales, de clase social, de identidad; para generar y poner en práctica distintos tipos de valores (Skliar, 2007).

En este sentido, la educación constituye la tarea de volverse más humano. La educación es un proceso que une a dos o más personas para así ponerlas en situación de comunicación, de intercambio y de transformación reciproca. Es el acto de resistencia donde se pasa de yoísmo a la filantropía (Bárcena, 2012; Fernández y Sarmiento, 2014) porque maestros y maestras se interesan por el encuentro con el Otro: "sin esa resistencia no hay arte de educar como arte de tejer encuentro" (Skliar y Tellez, 2008, p.143).

\section{La vocación del ser del profesorado}

Sobre el cuerpo docente, son múltiples las miradas y caracterizaciones que desde las diferentes ramas de la ciencia como la psicología, antropología, sociología y medicina se han estipulado. Varias de esas taxonomías reconocen que el profesorado debe cumplir ciertos requisitos de orden académico, profesional, moral y estético para ejercer su quehacer. No obstante, hace falta volver a la raíz que origina su figura e importancia en la sociedad: la vocación.

La palabra vocación proviene del latín vocare que alude a un llamado a determinado fin o destino (Pantoja, 1992). Viene de vox: la voz que requiere de alguien quien la acoja (Zambrano, 1965). Según Cuelí (1985) “es el llamado a cumplir una necesidad que cada persona oye y siente a su manera: es un impulso, una urgencia, una necesidad insatisfecha" (p.68). Por el contrario, Mounier (2000) manifiesta que la vocación es un principio creador donde se descubre progresivamente la finalidad de la existencia, por consiguiente, es una construcción y un proceso de formación continua que hace el sujeto por medio de su disposición para elegir su camino (profesión u oficio) de acuerdo con sus aptitudes, características psicológicas y físicas, motivaciones y marcos de referencia socio-económicos y culturales (D’Egremy, 1982; Pantoja, 1992).

Es así como de acuerdo con Corts (2002), docentes por vocación presentan las siguientes dimensiones: (1) Dimensión de aprendizaje: presentar convicción de su arte y la importancia de la especialización en la disciplina que le compete. (2) Dimensión metodológica: no le basta con saber conocimientos, también se le hace necesario saber aplicarlos y transmitirlos (3) Dimensión experiencial-espiritual: se siente en plenitud puesto en su propia experiencia descubre la verdad y afirma valores (Gusdorf, 1980).

Dado lo anterior, la vocación de las personas educadoras "no se refiere exclusivamente a la dirección o meta, sentimiento o emoción, lógica, significado o placer; es algo más” (Martínez, 2009, p.12). Es una disposición a la excentricidad: a salir de sí mismo, a donar-se al Otro porque es en la dadivosidad que el profesorado logra un signo: dejar huella (Alliaud y Antelo, 2011). El cuerpo docentes entonces es quien "abre un espacio de acogida donde el otro pueda habitar" (Bárcena, 2012, p.79), donde la comunicación de un saber se hace 
mediante la palabra anticipada que, a su vez, sugiere la creación de la propia palabra del Otro. De manera que, para el profesorado, el amor, es uno de los elementos que marca la diferencia en su vocación.

\section{La responsabilidad: responder a la pregunta del Otro}

En el acto educativo el profesorado se pregunta por variadas situaciones, hechos y acontecimientos a los cuales deben dar solución para poder llevar a cabo su quehacer. No obstante, ninguna de las anteriores podría resolverse si su pregunta no comienza por la diferencia, la presencia y por la ausencia del Otro. Es en el rostro del Otro que las personas educadoras se interrogan hasta la urgencia de darle respuesta. Es allí donde sienten que "el Otro tiene que ver consigo y, por tanto, se hace imprescindible hacerse cargo" (Lévinas, 2012, p.216).

De esta manera, la responsabilidad trasciende las esferas tradicionales que la coartan en la tradicional definición de "asumir las consecuencias de determinadas conductas" (Isaacs, 2002, p.133). Responsabilidad proviene del latín responderé que alude a la capacidad de responder, de resolver y de atender. Por esa razón, la responsabilidad se establece en una relación ética con el Otro, que, sin conocer a priori, motiva la donación. Los y las docentes al estar en presencia con el Otro presenta la necesidad de darle respuesta: ser responsable (Lévinas, 2014).

Así, la responsabilidad se constituye en un comienzo en el Otro: con su presencia, su lejanía, su cercanía, con su palabra y su misterio, es decir, un Otro que coloca, que entrega, que ofrece lo suyo (Skliar, 2005). Por consiguiente, maestros y maestras hacen las cosas por el Otro, para el Otro y con los Otros (Antelo, 2009). La primera, implica un gesto de sacrificio por querer el bienestar de los educandos. La segunda, hace referencia a la adhesión de determinadas ideas pedagógicas-educativas y defensa de estas. La tercera, alude a una forma de convencimiento: vencer con el otro. No para, ni por, ni contra el otro. Con el Otro (Freire, 2008).

Dado lo anterior, la responsabilidad requiere de las y los educadores según Ortega (2014): (1) una renuncia al yo para que el Otro sea reconocido; (2) Asumir la vulnerabilidad humana del Otro, elevándolo; (3) Salir al encuentro del Otro desde su realidad; (4) Ver en el Otro lo que otros no ven, mirar con la mirada interior de la compasión; (5) Entender la tarea educativa como un acto de amor: de entrega y de donación de sí y de sus saberes

Ser responsable entonces se refiere a estar atento, a "escuchar de verdad a quien tenemos delante" (Bárcena, 2016, p.193) para darle respuesta a sus aspiraciones que se expresan desde situaciones, lugares y lenguajes diferentes y que llevan consigo un rostro. Se responde a alguien que descentra y saca al educador de sí mismo para situarse al otro lado y así, preocuparse y ocuparse de este (Romero y Gutiérrez, 2011). Se responde para brindar hospedaje y acogida porque se dota al Otro de importancia: para que importe lo que le pasa hay que verlo y para verlo hay que amarlo (Maturana, 1996).

\section{Procedimientos metodológicos}

\section{Tipo de estudio}

Este estudio se asume desde la investigación cualitativa, la cual

aborda lo real en cuanto proceso cultural, desde una perspectiva subjetiva, con la que se intenta comprender e interpretar todas las acciones humanas, las vivencias, las experiencias, y los sentires, con el fin de crear formas de ser en el mundo (Portilla, Rojas y Hernández, 2014, p.91).

La investigación cualitativa se orienta a comprender la perspectiva de cada participante acerca de los fenómenos que le rodean, profundizar en sus experiencias, perspectivas, opiniones y significados, es decir, 
"la forma en que los participantes perciben subjetivamente su realidad" (Hernández, Fernández y Baptista, 2010, p.364).

En este sentido, se pretende comprender y explicar las formas como el cuerpo docente piensa, vive y expresa su responsabilidad educativa, a partir de su ámbito de desempeño cotidiano. Con ello, se busca explorar la realidad del profesorado, teniendo como base las experiencias subjetivas de la responsabilidad en el encuentro con sus estudiantes.

\section{Método: la fenomenología}

La fenomenología, como método de investigación, consistente en describir las estructuras básicas de la experiencia vivida (Van Manen, 2016). Estudia de manera sistemática el mundo percibido en relación con el sujeto y el objeto que se unen por medio de la idea de estar en el mundo y así tener acceso a la vivencia (De la Cuesta, 2006). Se interesa por la verdadera esencia de los fenómenos o de los hechos sociales para pensar sobre la experiencia originaria y conocer los significados que los sujetos le atribuyen a esa experiencia (Monje, 2011). Es así, como la fenomenología surge como un compromiso con la descripción y la clarificación de la estructura esencial del mundo vivido, meditando sobre los orígenes de la experiencia: "es un camino alternativo para entender cómo y dónde se origina y ocurre inicialmente el sentido" (Husserl citado en Van Manen, 2016, p.27).

Para efectos del presente estudio, se busca sacar a relucir la experiencia de profesores y profesoras con relación su responsabilidad educativa a fin de recuperar y expresar los modos en que lo vivencian. Por dicha razón, se describe e interpreta este fenómeno desde ellos mismos: "la fenomenología significa dejar que lo que se muestra a sí mismo sea visto desde sí mismo" (Heidegger, 2010, p.32)

\section{Fenomenología de la responsabilidad}

Emmanuel Lévinas señala que, en la relación de un sujeto con un rostro, el sujeto se aproxima al Otro reduciendo la distancia entre ambos lo cual suscita una preocupación atenta por ese Otro: la otredad (Van Manen, 2016). Es especialmente el rostro el que da significado a la responsabilidad. Desde esta perspectiva, volcar la mirada hacia el rostro es una forma de conocimiento y una entrada ética (Lévinas, 1991) pues la responsabilidad está orientada a lo humano como primer deber (Van Manen, 2016). Todo sujeto es reclamado ante el llamado del Otro que se hace como una exigencia. Así el individuo se reconoce como una persona responsable por este Otro único.

Desde esta perspectiva, la fenomenología de la responsabilidad por el Otro está mediada por la escucha al llamado del Otro entendida como el encuentro que surge entre los sujetos por la disposición de estar para el Otro antes de que este lo reclame. De esta manera, el sujeto que se responsabiliza presenta una actitud de preocupación, una capacidad de apertura, una inclinación a la renuncia, una forma de donación y una afectación con el Otro. En este sentido, la fenomenología de la responsabilidad es una vocación por el Otro.

\section{Existenciales para la fenomenología de la responsabilidad}

Para la fenomenología de la responsabilidad un modo de acercarse al fenómeno es a través de los existenciales. Para ello, se elaboran y establecen las categorías propias de esta fenomenología y se vinculan los existenciales propuestos por el fenomenólogo de la práctica Max Van Manen (2016). En relación con la fenomenología de la responsabilidad los existenciales establecidos son: la renuncia de sí mismo (por el otro), la preocupación (por el otro), la apertura (al otro), la donación de sí mismo (para el otro) y la afectación (con el otro). Por parte de 
Tany Giselle Fernández Guayana. Fenomenología de la responsabilidad por el Otro: un estudio sobre ...

Max Van Manen (2016) se vinculan los existenciales de: la espacialidad (el espacio vivido), la temporalidad (el tiempo vivido), y la materialidad (cosas y tecnología vivida) (ver Tabla 1). 
Revista Educación, 2020, 44(1), Enero-Junio, ISSN: 0379-7082 / 2215-2644

TABLA 1

Existenciales para la fenomenología de la responsabilidad

\begin{tabular}{|c|c|}
\hline \multicolumn{2}{|c|}{ Fenomenología de la responsabilidad } \\
\hline $\begin{array}{l}\text { Renuncia de sí } \\
\text { mismo por el Otro }\end{array}$ & $\begin{array}{l}\text { Supera toda lógica de reciprocidad. El } \\
\text { sujeto que renuncia realiza un acto de } \\
\text { sacrificio personal donde se desprende de } \\
\text { su yo (prejuicios, limitantes, expectativas y } \\
\text { esquemas) a fin de tomar una actitud de } \\
\text { apertura con el Otro. Es la experiencia de } \\
\text { estar presente para el Otro } \\
\text { independientemente de si este lo pide o no. } \\
\text { Se renuncia por el hecho de que el Otro es } \\
\text { importante y digno de atención y cuidado. } \\
\text { La renuncia se manifiesta al anteponer al } \\
\text { Otro antes que la imagen prefijada de este. }\end{array}$ \\
\hline $\begin{array}{l}\text { Preocupación por el } \\
\text { Otro: }\end{array}$ & $\begin{array}{l}\text { Se manifiesta a través de la relación ética. } \\
\text { El individuo se sensibiliza ante la presencia } \\
\text { del Otro independientemente de lo que este } \\
\text { sienta, piense, haga y sin importar el sexo, } \\
\text { la raza, condición social o cultura. El sujeto } \\
\text { reconoce que tiene a su cargo Otro a quien } \\
\text { debe responder mucho antes de que este lo } \\
\text { llame; es así como la presencia del Otro lo } \\
\text { hace responsable para ocuparse de él y } \\
\text { acompañarlo en un aquí y en un ahora. }\end{array}$ \\
\hline Apertura al Otro: & $\begin{array}{l}\text { Se refiere a una actitud de acogimiento, de } \\
\text { hospitalidad y de cuidado del Otro, ante su } \\
\text { presencia desbordante. Consiste, en recibir } \\
\text { todo lo que ese Otro es en su humanidad. } \\
\text { De manera que, el sujeto quien recibe, así } \\
\text { no se encuentre preparado en términos } \\
\text { materiales o intelectuales para su } \\
\text { demanda, es capaz de acogerlo sin } \\
\text { prejuicios a fin de no dejarlo solo. }\end{array}$ \\
\hline $\begin{array}{l}\text { Donación de sí } \\
\text { mismo para el Otro: }\end{array}$ & $\begin{array}{l}\text { Tiene que ver con capacidad de entregar lo } \\
\text { que se tiene y lo que se es como ser } \\
\text { humano. La donación se da cuando un } \\
\text { sujeto se brinda plenamente ante la } \\
\text { presencia del Otro, sin que este lo esté } \\
\text { solicitando previamente. El individuo dona } \\
\text { todo aun cuando no sea suficiente para el } \\
\text { Otro. El decir síante la epifania del Otro es } \\
\text { la forma de la donación. }\end{array}$ \\
\hline $\begin{array}{l}\text { Afectación con el } \\
\text { Otro }\end{array}$ & $\begin{array}{l}\text { Se presenta en la medida que el sujeto se } \\
\text { deja alterar corporal y afectivamente por la } \\
\text { presencia del Otro. De modo que surge en } \\
\text { el sujeto un cambio personal. Se manifiesta } \\
\text { cuando el individuo se siente alterado por } \\
\text { lo que le sucede al Otro cambiando su } \\
\text { perspectiva frente a la realidad del Otro. } \\
\text { Alli se vuelve consciente de la relación } \\
\text { ética: hay un acto en doble via donde son } \\
\text { el sujeto y el Otro, quienes son } \\
\text { influenciados. }\end{array}$ \\
\hline Espacialidad & $\begin{array}{l}\text { Se refiere a todo lugar particular que } \\
\text { condiciona o da lugar a la experiencia. } \\
\text { Todo fenómeno social, surge en un espacio } \\
\text { donde se habita y se construyen relaciones. } \\
\text { Por consiguiente, toda experiencia vivida } \\
\text { conlleva un escenario de encuentro que no } \\
\text { se limita a espacios institucionalizados ni a } \\
\text { roles determinados. }\end{array}$ \\
\hline Temporalidad & $\begin{array}{l}\text { Todo fenómeno requiere de un momento } \\
\text { para que se manifieste. El fenómeno surge } \\
\text { entre el tiempo Cronos (medible, } \\
\text { verificable, lineal) y el tiempo Kairos (la } \\
\text { experiencia vivida) o, dicho de otra } \\
\text { manera, entre el tiempo objetivo (del reloj) } \\
\text { y el tiempo subjetivo (fenomenológico). } \\
\text { Todo fenómeno se manifiesta en un } \\
\text { momento y se recoge como experiencia } \\
\text { vivida. }\end{array}$ \\
\hline Materialidad & $\begin{array}{l}\text { La materialidad hace referencia al } \\
\text { significado de las cosas en la vida de los } \\
\text { sujetos y que, a su vez, median en las } \\
\text { relaciones. Aqui, se manifiesta cómo son } \\
\text { vivenciadas las cosas y cómo contribuyen } \\
\text { al sentido del sujeto. La materialidad se } \\
\text { manifiesta a través de los objetos } \\
\text { materiales tales como elementos tangibles } \\
\text { y las cosas inmateriales tales como las } \\
\text { ideas, las acciones, las vivencias, los } \\
\text { acontecimientos, las actitudes, las } \\
\text { aptitudes, descubrimientos y los valores. }\end{array}$ \\
\hline
\end{tabular}


Fuente: Elaboración propia

\section{Criterios de selección}

Se contó con la participación de profesores y profesoras que se encontraran en ejercicio y que se desempeñaran en los diferentes niveles de formación según el sistema educativo colombiano: preescolar, educación primaria, secundaria y media, educación universitaria y posgradual. De manera intencionada se establecieron diez (10) docentes: un (1) profesor y una (1) profesora por cada nivel de formación bajo el criterio de accesibilidad. De esta manera se entrevistaron: tres (3) en los niveles de Preescolar y Educación Media de instituciones privadas; cuatro (4) en los niveles de Educación Superior de instituciones privadas; dos (2) de Educación Básica de instituciones públicas; Uno (1) de Preescolar y Básica Primaria de institución pública.

\section{Técnica de recolección de información}

Se utilizó la entrevista fenomenológica propuesta por Max Van Manen (2016) la cual permite ir al origen y a la experiencia misma sin intervención emocional o teórica por parte de la persona investigadora. La entrevista fenomenológica es aquella en la cual quien investiga hace una indagación exhaustiva para lograr que el entrevistado hable libremente y exprese en forma detallada sus experiencias vividas sobre el fenómeno de estudio. Es una técnica que se utiliza para explorar y recoger material narrativo vivencial como historias o anécdotas, dando lugar a una relación sustentada en la confianza en la cual fluye la confidencia e inclusive la información que normalmente se oculta o no se comparte con nadie (Kornblit, 2004; Van Manen, 2016). (Ver Tabla 2).

TABLA 2

Entrevista fenomenológica para la fenomenología de la responsabilidad

\begin{tabular}{ll}
\hline PREGUNTA & PREGUNTA \\
\hline P1. & $\begin{array}{l}\text { Cuénteme las experiencias que haya } \\
\text { tenido, donde un estudiante lo } \\
\text { desestabilizó tanto que generó una } \\
\text { transformación en usted. }\end{array}$ \\
\hline P2. Renuncia & $\begin{array}{l}\text { ¿A qué renuncio usted en ese } \\
\text { encuentro/experiencia/momento? } \\
\text { ¿Qué preocupación hubo por su } \\
\text { P3. Preocupación } \\
\text { encudiante en ese }\end{array}$ \\
\hline P4. Apertura & $\begin{array}{l}\text { ¿Cómo antepuso a su estudiante en ese } \\
\text { encuentro/experiencia/momento? }\end{array}$ \\
P5. Donación & $\begin{array}{l}\text { ¿Qué cosas materiales o inmateriales } \\
\text { entregó de usted mismo en ese } \\
\text { encuentro/experiencia/momento? }\end{array}$ \\
P6. Afectación & $\begin{array}{l}\text { ¿Cómo le afectó ese } \\
\text { encuentro/experiencia a nivel personal y } \\
\text { profesional? }\end{array}$ \\
\hline
\end{tabular}

Fuente: Elaboración propia 


\section{Procedimiento y análisis de datos (Ver figura 1)}

Una vez obtenidas las anécdotas del profesorado, se digitaron cada una de ellas mediante la aplicación web oTranscribe. Para la selección de las anécdotas, se filtró la información de la siguiente manera: a) Se centró la atención en la vivencia, evitando opiniones, percepciones, creencias, generalización e interpretaciones acerca de esta. b) Se tuvieron en cuenta las descripciones vividas desde los sentimientos y actitudes. c) Se centró la atención en un evento particular de la vivencia: momento donde las y los educadores vivieron la responsabilidad educativa. De esta manera, las anécdotas escogidas son editadas sin distorsionar la vivencia original. Posteriormente, cada anécdota es codificada según el participante y el número de anécdotas que haya aportado. Para ello se utiliza la siguiente nomenclatura: $\mathbf{m \# . a \# ~ d o n d e ~} \mathrm{m} \#$ hace referencia al profesor $\mathrm{y}$ profesora en particular y a\# a las vivencias. Luego, se elabora una matriz a partir del programa Excel donde se organizan cada uno de los existenciales de la presente investigación (en la fila superior) así como cada una de las anécdotas (en la columna).

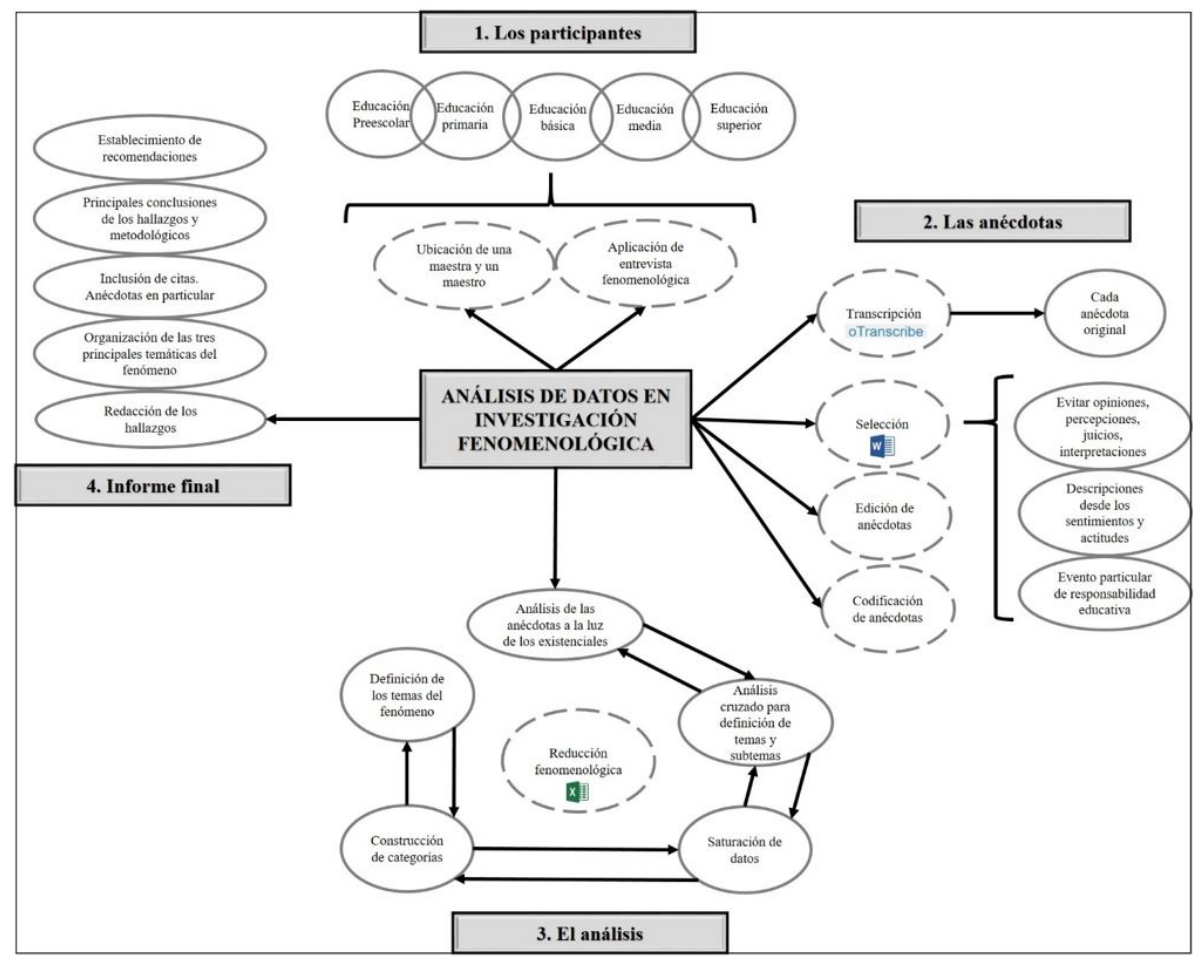

FIGURA 1

Procedimiento de análisis de datos fenomenológico

Fuente: Elaboración propia

Allí se cruzan los datos a fin de explorar aspectos significativos del fenómeno y cómo se presenta en medio de los existenciales. Seguido, se elabora el análisis temático donde se recuperan las estructuras de sentido que están implicadas en las vivencias de la responsabilidad educativa de los y las docentes. Para ello, se acude a la reducción fenomenológica (Van Manen, 2016) atendiendo las vivencias como fuentes de sentido a nivel holístico de la narración. Posteriormente, se saturan los datos obtenidos a fin de agrupar las temáticas y dar cabida a los elementos que posibilitan la vivencia del fenómeno en su sentido original. Finalmente, se redactan los hallazgos teniendo en cuenta las temáticas arrojadas por la matriz con sus respectivos temas y subtemas (Ver Tabla 3). De allí, surge la sistematización descriptiva, minuciosa y detallada de lo encontrado en las anécdotas y que dan fe del fenómeno. Adicional, se agregan algunas citas por parte de los entrevistados para dar claridad al texto y ejemplificación. Luego, se hace un cierre condensando los 
Tany Giselle Fernández Guayana. Fenomenología de la responsabilidad por el Otro: un estudio sobre ...

principales hallazgos investigativos y metodológicos, así como el establecimiento de algunas recomendaciones para futuros estudios que se interesen en retomar la fenomenología de la responsabilidad.

TABLA 3

Estructura de temas y subtemas para el análisis de una fenomenología de la responsabilidad como vocación por el Otro.

\begin{tabular}{|c|c|c|}
\hline \multirow{5}{*}{$\begin{array}{l}\text { TEMAS } \\
\text { La } \\
\text { responsabilidad } \\
\text { como comienzo en } \\
\text { el sí mismo }\end{array}$} & \multicolumn{2}{|l|}{ SUBTEMAS } \\
\hline & $\begin{array}{l}\text { Abandono del } \\
\text { ruido que opaca al } \\
\text { Otro }\end{array}$ & $\begin{array}{l}\text { No dejarse llevar } \\
\text { Romper los } \\
\text { esquemas } \\
\text { Contenerse de } \\
\text { actuar a la primera }\end{array}$ \\
\hline & $\begin{array}{l}\text { Disposición ante } \\
\text { la presencia del } \\
\text { Otro }\end{array}$ & $\begin{array}{l}\text { Disposición ante el } \\
\text { Otro Actitud de } \\
\text { acogida Asumir el } \\
\text { rol }\end{array}$ \\
\hline & $\begin{array}{l}\text { Estar presente } \\
\text { para el Otro }\end{array}$ & $\begin{array}{l}\text { Generar cercanía } \\
\text { Agotar los recursos } \\
\text { Insistencia }\end{array}$ \\
\hline & Asumir al Otro & $\begin{array}{l}\text { Valoración del Otro } \\
\text { Preocupación } \\
\text { Responsabilidad y } \\
\text { deber Aceptación de } \\
\text { los errores }\end{array}$ \\
\hline \multirow{4}{*}{$\begin{array}{l}\quad \text { La } \\
\text { responsabilidad } \\
\text { ante la presencia } \\
\text { desbordante del } \\
\text { Otro }\end{array}$} & $\begin{array}{l}\text { Tener propósitos } \\
\text { con el Otro }\end{array}$ & $\begin{array}{l}\text { Acercarse al Otro } \\
\text { Abrir los horizontes } \\
\text { Intencionalidad con } \\
\text { el Otro }\end{array}$ \\
\hline & $\begin{array}{l}\text { Proceder para el } \\
\text { Otro }\end{array}$ & $\begin{array}{l}\text { Ponerse en acción } \\
\text { Desafiar lo } \\
\text { establecido Interés } \\
\text { por mejorar }\end{array}$ \\
\hline & Lo interno al yo & $\begin{array}{l}\text { Los valores El } \\
\text { mundo interior La } \\
\text { personalidad Lo } \\
\text { corpóreo }\end{array}$ \\
\hline & Lo externo al yo & Objetos Relaciones \\
\hline \multirow[t]{4}{*}{$\begin{array}{l}\text { La } \\
\text { responsabilidad } \\
\text { como respuesta } \\
\text { ética ante el Otro }\end{array}$} & $\begin{array}{l}\text { Permitirse alterar } \\
\text { por el Otro }\end{array}$ & $\begin{array}{l}\text { Dejarse tocar por el } \\
\text { Otro Sentidos } \\
\text { atentos } \\
\text { Cuestionarse por el } \\
\text { Otro Aceptar la } \\
\text { realidad }\end{array}$ \\
\hline & $\begin{array}{l}\text { Conmoción por el } \\
\text { Otro }\end{array}$ & $\begin{array}{l}\text { Emociones de } \\
\text { alegria Emociones } \\
\text { de dolor Emociones } \\
\text { de enfado } \\
\text { Emociones de horror } \\
\text { Emociones de } \\
\text { intranquilidad } \\
\text { Emociones de } \\
\text { resistencia } \\
\text { Emociones } \\
\text { ambiguas }\end{array}$ \\
\hline & $\begin{array}{l}\text { Apertura al } \\
\text { cambio para el } \\
\text { Otro }\end{array}$ & $\begin{array}{l}\text { Toma de conciencia } \\
\text { según el Otro Toma } \\
\text { de conciencia según } \\
\text { el rol de cada } \\
\text { docente }\end{array}$ \\
\hline & $\begin{array}{l}\text { Transformarse } \\
\text { para el Otro }\end{array}$ & $\begin{array}{l}\text { Dejar los prejuicios } \\
\text { Interés por el } \\
\text { cambio Arriesgarse } \\
\text { para el Otro }\end{array}$ \\
\hline
\end{tabular}




\section{ANÁLISIS Y HALLAZGOS}

\section{La responsabilidad como comienzo en el sí mismo}

Para cada maestra o maestro entrevistado, la responsabilidad educativa tiene un comienzo. Se caracteriza por el proceso de introspección permanente que les invita a desprenderse de los juicios que estigmatizan y así poder asumir al Otro. Consideran que en la responsabilidad educativa surge un abandono del ruido que opaca al Otro para presentar una mejor disposición ante su presencia, independiente de cómo este se manifieste, de sus características físicas, de conducta o su pasado. A causa de ello, logran desprenderse de los juicios para asumir al Otro.

\subsection{Abandono del ruido que opaca al Otro}

Según el profesorado, se requiere de una disposición propia para no dejarse contaminar de lo que acontece alrededor de la imagen de sus estudiantes. También se requiere de una disposición de apertura a fin de no seguir los esquemas que limitan el acto educativo de la enseñanza. De igual manera, se requiere de una disposición para querer controlar los impulsos que ejercen autoridad y que estigmatizan al Otro por la forma en como este se presenta. En este sentido, para los y las docentes, el abandono del ruido que opaca al Otro acontece en el silencio para saber recibir al Otro; en la trasgresión de lo instaurado para saber acercarse al Otro; y en la evitación de ejercicios de poder para no disminuir al Otro.

\footnotetext{
Según comenta la psicóloga, ha sido diagnosticado por TDAH. Los demás profesores solo expresan que 'es mamón y fastidioso'. No niego que su indisciplina es notoria, sin embargo, presenta una gran inteligencia, comprende fácilmente, argumenta bastante bien y se le facilita la oralidad, lo que no le gusta es escribir (m6.a5, comunicación personal, 20 de diciembre, 2018)

Al saber lo que sucede, he comenzado a cambiar de actitud: me he tornado aún más cariñosa, estoy pendiente de ella, de sus amigas, y a le suelo preguntar: '‘anoche dormiste sola? Si necesitas algo, dímelo, yo estoy pendiente de ti' (m1.al, comunicación personal, 11 de diciembre, 2018)
}

\subsection{Disposición ante la presencia del Otro}

Para las personas educadoras, en la disposición ante la presencia del Otro se hace imprescindible estar en el aquí y en el ahora, estar para sus estudiantes. También se requiere de una actitud de recibimiento y de hospitalidad que interpela protección. A partir de ello, logran asumir su rol como un acto formativo y crítico a fin de entregarse integralmente a todos los que surge alrededor de sus educandos. Dado lo anterior, los maestros y maestras viven la disposición ante la presenta del Otro en la medida que se están presente en cuerpo y espíritu para la revelación del Otro; en la medida que disponen los medios para recibir a quien está fuera de su esfera personal; y en la medida que su rol es asumido como un acto de reflexión para reconocer al Otro.

Yo sospecho que algo raro le está sucediendo, tal vez porque doy estos temas humanísticos o porque soy madre, así que le envío mi WhatsApp, me afana que se encuentre sola (m7.a1, comunicación personal, 14 de enero, 2019).

$\mathrm{Al}$ escucharme a mí mismo en mi propio discurso, me percato de la necesidad de cambiar la didáctica. Me es necesario enganchar y sacudir a los estudiantes ante las realidades humanas. Así que, consulto sobre pedagogía, didácticas y hasta terapias, para implementarlas desde el siguiente semestre (m8.a4, comunicación personal, 31 de enero, 2019). 


\subsection{Estar presente para el Otro}

De acuerdo con las anécdotas del personal docente, estar presente para el Otro se experimenta en la cercanía, por tanto, agotan los recursos una vez comparten con sus estudiantes y los conocen. Gracias a ello, insisten en una búsqueda del bienestar de sus educandos. Es así como, para el profesorado, el estar presente para el Otro acontece en la proximidad, en disponerse hacia Otro; en el hacer todo lo posible para reducir lo que perjudica al Otro; y en el empeño por lograr unos objetivos pedagógicos con el Otro.

Un día, en ese espacio, él me comenta: 'yo soy homosexual'. Yo me impacto por dentro, esta es la primera vez que tengo de cerca una persona así y no me lo esperaba de él, especialmente por todo lo que hemos compartido. Sin embargo, lo que viene a mi mente es: ¿se encontrará bien?, ¿cómo puedo ayudarlo?, si me está buscando es por algo (m9.a1, comunicación personal, 15 de enero, 2019).

¿Por qué hago todo esto corriendo altos riesgos de ser despedida o de insultos? Sencillo, yo me siento co-responsable de su desarrollo. Esta es una forma de estar tranquila conmigo misma, de saber que estoy haciendo bien mi trabajo (m5.a2, comunicación personal, 12 de diciembre, 2018).

\subsection{Asumir al Otro}

Concorde a los aportes del profesorado, para asumir al Otro se hace imprescindible contar con la disposición propia de valorar al Otro y dejarse cautivar por su presencia. Gracias a ello, sienten que es su responsabilidad hacer algo por sus estudiantes y, por lo tanto, se compromete con ellos. De esta manera, se motivan asumiendo cada caso como un reto, pues en la medida que ejercen su quehacer, se mejora así mismo también. En este sentido, para las y los educadores el asumir al Otro sucede al momento de reconocen la realidad que vive el Otro; al momento que se inquietan y se hacen cargo de su epifanía constante; al momento de establecer acuerdos en el quehacer diario; y al momento de reconocer su natural exposición a la equivocación.

En este caso particular me doy cuenta de la importancia de renunciar al esquema formal del profesor universitario que llega a dictar su clase, sin siquiera saber quiénes están allí... Es nuestra responsabilidad preguntar qué les pasa y estar pendiente de ellos, porque al final, lo que tenemos a cargo son vidas (m10.a8, comunicación personal, 22 de enero, 2019).

E. simplemente me ha mirado con los ojos aguados y me pregunta: ¿por qué me quita el dulce?, yo no le respondo por qué, pues en ese mismo momento me siento culpable, con remordimiento, ella es una niña de cinco años... había podido guardárselo para después (m4.a1, comunicación personal, 5 de marzo, 2019).

\section{La responsabilidad ante la presencia desbordante del Otro}

El personal docente entrevistado expresa que es responsabilidad de ellos, una serie de actividades y tareas que surgen en la misión de educar. Además de estudiar su ciencia, han de mejorarse a sí mismos para orientar a sus estudiantes. De esta manera, recalcan que la educación es sinónimo de relación con el Otro, una coexistencia. Una relación donde el yo entra en contacto a partir de la presencia viva del Otro. Una relación donde maestros, maestras y estudiantes entran en contacto a partir de la intención pedagógica. En razón de ello, el profesorado actúa, hace y procede para el Otro con una serie de elementos que están dentro y fuera de si mismos, a fin de responder a la presencia desbordante del Otro.

\subsection{Tener propósito con el Otro}

Para las maestras y los maestros tener propósito con el Otro es la forma predilecta de disponerse a la epifanía de sus estudiantes. Mencionan que, para ello, se requiere de la plena conciencia para decidir acercarse al Otro. Por eso, la pregunta es su herramienta predilecta ya que va dirigida a un rostro. Una vez la pregunta surge 
su efecto, los y las estudiantes se abren a sus educadores ayudándolos a ampliar sus horizontes respecto a la imagen prefijada que tengan de estos. Gracias a esta disposición de apertura, Los y las docentes son capaces de tomar decisiones acordes a la situación que presentan sus educandos estableciendo allí, una intencionalidad pedagógica. En resumen, para el profesorado, tener propósito con el Otro, acontece en la inquietud que genera la presencia del Otro; en el interés por resolver; y en la voluntad de responder al estudiante.

... se me presentaron varias opciones: seguir llorando, renunciar al cargo o hacer algo. Opto por la tercera. Allí me doy cuenta, que se me ha olvidado, que estoy trabajando con seres humanos. Ha imperado en mí la trasmisión del conocimiento en vez de reconocer la emocionalidad del otro y su contexto biográfico (m3.al, comunicación personal, 23 de febrero, 2019).

Esta experiencia, a pesar de lo dura que ha sido para mí, me ha enseñado que uno no está para recriminar sino para cuidar, por mucho que nos duelan las decisiones que toman nuestros estudiantes (m7.a2, comunicación personal, 14 de enero, 2019).

\subsection{Proceder para el Otro}

En relación con lo manifestado por el profesorado, se hace ineludible proceder una vez se haya percatado de la revelación del Otro. Al proceder para el Otro, experimentan la necesidad de ayudar, orientar, formar y cuidar a sus estudiantes. Por esa razón, desafían lo que se establece de forma estandarizada sin tener en cuenta las particularidades y urgencias que puedan presentar sus educandos. Incluso, enfocan sus esfuerzos por mejorar en su propia práctica y pensamiento. En suma, los y las docentes proceden para el Otro en la constante intervención, es decir, en lo que le sucede y en lo que rodea a sus estudiantes; al asumir como reto la presencia del Otro: quien es, lo que trae consigo y sus ausencias; y en el acto de ceder, forma predilecta para dirigida al Otro.

Viendo la situación, me pongo en contacto con el titular de química de su colegio, quien es amigo mío. Al contarle lo que estaba sucediendo con Jennifer, él expresa el mismo sentimiento, así que comenzamos a trabajar en conjunto (m5.a2, comunicación personal, 12 de diciembre, 2018).

También voy hasta su casa cuando se ausentan, aun sabiendo que es riesgoso, pero voy y les expreso que me hacen falta, que sin ellos la escuela no es igual (m2.a1, comunicación personal, 23 de febrero, 2019).

\subsection{Conceder al Otro lo interno al si mismo}

Por la presencia desbordante del Otro maestros y maestras se motivan a la entrega de todo lo que son, de todo lo que tienen e incluso, de todo lo que les falta, reconociéndolo. Y con ello, viven la capacidad de conceder al Otro lo interno al sí mismo como una forma de don. Según se evidencia en sus anécdotas, la capacidad dadivosa les permite brindarse sin requisitos y sin reciprocidades, sin esperar nada a cambio, porque, a la larga, la entrega de los valores, del mundo interior, de la personalidad y de la corporeidad, se tornan en rasgos inmanentes de su ser -de los cuales es imposible desprenderse- y en un ejercicio inmanente de responsabilidad educativa.

Justo todo estalla cuando hago el remplazo, pero debí enfrentarlo, estas son cosas que no dan tiempo: 'esperemos a que la coordinadora llegue y coja la situación', no, a mí me toca investigar y hacer algo... Esto me ha transformado porque, aunque no parezca, yo soy tímida y esta experiencia me ha permitido sacar agallas. La yo de antes no habría sido capaz, pero, el hecho de tener un niño, ahí frente a tus ojos, hace cambios en uno: yo tengo una responsabilidad con ellos (m1.a5, comunicación personal, 11 de diciembre, 2018).

Ella me insiste en el tema hasta que confiesa una serie de acontecimientos de maltrato que ha vivido al interior de su familia. Yo lo único que hago es escuchar, verla llorar... y la abrazo (m6.a2, comunicación personal, 20 de diciembre, 2018). 


\subsection{Conceder al Otro lo externo al sí mismo}

La vivencia del conceder al Otro lo externo al sí mismo, para el profesorado, sucede al momento en que, ante la presencia desbordante de sus educandos, entregan tanto lo material como lo inmaterial, tanto lo que tienen como lo que no, símbolo de la donación plena del ser en el acto educativo. Las personas educadoras entonces viven un vaciamiento de sí mismas cuando son capaces de compartir cosas materiales e inmateriales como objetos o relaciones que, en primera instancia, tienen que ver consigo mismas.

Con el tiempo la mamá me pide ser el padrino de D. y yo acepto hasta el punto de quererlo como si fuera mi propio hijo, hasta le abro una cuenta en la cafetería para que pueda pedir lo que quiera (m10.a4, comunicación personal, 22 de enero, 2019).

Hasta que un día me dice: 'yo quiero ser curado'. Eso me ha sorprendido porque mi intención no es curarlo. Viendo la situación, le soy honesta y le digo: 'mira, yo no soy experta en ese tema, pero te puedo hacer los contactos para que inicies con los profesionales correspondiente’ (m9.a1, comunicación personal, 15 de enero, 2019).

\section{La responsabilidad como respuesta ética ante el Otro}

El profesorado manifiesta que en el ejercicio educativo se intenta que el sistema responda a las demandas culturales y sociales sobre el individuo que desea formar para el futuro. Por su parte, ellos tienen como adicional, la relación directa con el Otro. Una relación que está marcada por el encuentro cara a cara, por el rostro expuesto que requiere de una respuesta diferente. De ahí que, consideran que deben permitirse a sí mismos, alterarse y conmocionarse por la presencia viva del Otro y disponerse a una apertura al cambio hasta el punto de transformarse profesional y personalmente.

\subsection{Permitirse alterarpor el Otro}

Según las anécdotas compartidas, los y las docentes se permiten alterar por el Otro, cuando presentan una disposición de apertura y se dejan tocar por la presencia del Otro. Gracias a ello, disponen sus sentidos alrededor de los comportamientos, conversaciones y actitudes de sus estudiantes a fin de adaptar su quehacer pedagógico a la realidad y contexto que los rodea. En efecto, permitirse alterar por el Otro, es vivida por profesores y profesoras a partir de la apertura mental, emocional y actitudinal para saber recibir la revelación del Otro sin límite y sin condiciones; es vivida a partir de la observación constante de lo que le acontece al Otro para toma de acción educativa; y es vivida a partir de una preocupación que genera la revelación del Otro.

El cansón de la clase ahora quiere participar, de seguro me quiere estropear el tema, pensé, sin embargo, le doy la palabra en el ejercicio de la Silla Vacía de su compañera: 'yo no estoy de acuerdo. Profesor, yo estuve paralizado de cintura para abajo hace unos años. Estaba postrado y no podía hacer nada, solo me lanzaba escaleras abajo y me daba contra las paredes. El ser humano es un ser completo, así como usted habló en clase, pero en esos momentos yo era incompleto así que ¿para qué insistir?'. Yo quedo mudo y la clase me mira. De repente, noto que ahora está funcional, así que le respondo: 'Entiendo, pero ahora estás bien'. Él contesta: 'Porque finalmente me hicieron una operación y funcionó, pero si eso no hubiera funcionado...'. Yo lo corto: 'Espera. Tú, que hoy estás bien, si tuvieras la oportunidad de hablar con tu yo del pasado, ¿qué le dirías (ejercicio de la Silla Vacía). No supo responder. Al finalizar la clase, este muchacho se me acerca: 'Profe, ¿podemos seguir hablando?'. Yo le brindo entonces mi número celular (m8.a3, comunicación personal, 31 de enero, 2019).

\subsection{Conmoción por el Otro}

Concorde a las anécdotas compartidas por las personas educadoras, no son suficientes los ejercicios académicos, hace falta la sensibilidad, la conmoción por el Otro: dejarse afectar emocionalmente. Así, 
la responsabilidad educativa se manifiesta al momento que se permiten experimentar y sentir diversas emociones como las de alegría, dolor, enfado, horror, intranquilidad y de resistencia. Sin embargo, aclaran que, permitirse sentir al Otro, detiene su rutina debido a que no pueden continuar hasta darle alguna solución a la presencia viva de sus estudiantes.

Gracias a esta experiencia, la cual me provoca alegría y satisfacción, se ha enrutado mi interés por seguir en la profesión docente (m4.a5, comunicación personal, 5 de marzo, 2019).

Nadie se imagina cómo me puse, porque a pesar de su mal desempeño y conducta, uno siempre tiene empatía con sus estudiantes, porque, al fin y al cabo, son las personas con las que estamos todos los días (m5.a3, comunicación personal, 12 de diciembre, 2018).

\subsection{Apertura al cambio}

Es relevante para el cuerpo docente que surja en ellos querer hacer modificaciones y cambios, no solo en su quehacer pedagógico, sino también en su propia forma de ver al Otro y cómo se relaciona con este. Por tanto, la toma de conciencia se torna en una de las respuestas predilectas ante la demanda del Otro. Las y los educadores aquí se dan cuenta de que todo lo que hacen y dejan de hacer tiene una repercusión directa en el Otro y en sí mismos, y, por tanto, pueden abrirse a la posibilidad de cambio. Es por esa razón que la apertura al cambio por el Otro es vivida como una toma de conciencia según el Otro y como una toma de conciencia según el rol de los profesores y profesoras.

Así que me he motivado muchísimo porque quiero que ellos aprendan y disfruten del uso del computador. No niego que también es mi intención tratar de quitar ese rótulo en el discurso del pueblo solo por el hecho de pertenecer a cierta institución (m4.a5, comunicación personal, 5 de marzo, 2019)

Considero que esta vivencia, fue detonante para hacer la Maestría en Educación y Desarrollo Humano, porque, mi interés principal es ampliar y conocer los procesos humanos, aprender a acoger sus lugares de enunciación, entender sus contextos y sus condiciones históricas, lo cual, en definitiva, me aporta como maestra en mi propio proceso humanizante (m3.a3, comunicación personal, 23 de febrero, 2019).

\subsection{Transformarse para el Otro}

Dada las experiencias de los maestros y maestras, la responsabilidad educativa es vivida en una constante toma de decisiones que posibilita transformación. En cada docente, la vivencia de la transformación para el Otro indica en ellos el afán de responder a la epifanía del educando. Es a partir del rostro y del encuentro con el Otro que atienden al llamado dejando de lado los prejuicios, interesándose por hacer un cambio en sí mismos y, por tanto, motivándose a tomar decisiones que a veces indican un riesgo personal o profesional. Por consiguiente, la transformación por el Otro es vivida por los y las docentes a partir de: la experiencia de la revelación donde se encuentra al Otro como un tú; la flexibilidad actitudinal hacia el Otro; y la capacidad de atreverse a fin de lograr su mejor versión por el bienestar del Otro.

También dejo de lado la estigmatización del otro, porque uno no sabe quién va a ser ese muchacho o muchacha en el futuro. En un proceso educativo, todos tienen derecho a ser gente y uno no es nadie para condenarlos a ser o no ser. (m10.a4, comunicación personal, 22 de enero, 2019).

Al ver la situación, recojo la comida y les digo: ‘No!, ¡Así no!, no hay comida entonces’ Los chicos salen despavoridos a contarle al rector. Cuando llega, este me regaña diciendo que lo que estoy haciendo es agresión, yo le respondo: 'si usted me desautoriza, si usted quiere que los chicos continúen así, yo me voy ya, yo no voy a desgastarme’ (m10.a1, comunicación personal, 22 de enero, 2019). 


\section{Conclusiones}

La vivencia de la responsabilidad educativa para el profesorado está colmada de una serie de imperativos ineludibles, de los cuales no pueden desprenderse y que en todo momento los lleva a la misma desembocadura: responder al Otro. Cabe aclarar que, en medio de las anécdotas compartidas por el profesorado, se evidencia la repetición de unos patrones que, para ellos, son inherentes a la labor de educar, pero que pocas veces son reconocidos a conciencia. Por consiguiente, viven la responsabilidad en medio de la cotidianeidad sin saber, de hecho, que están siendo responsables.

Es así como los sentidos de la responsabilidad educativa para maestros y maestras giran en torno al constante ir y venir de la reflexión del quehacer pedagógico hasta el punto de transformar su propia vida. Los sentidos de responsabilidad para el profesorado, surge a través de un proceso: inicia en ellos con el desprendimiento sí mismos, luego se abren a la presencia desbordante del Otro y, por último, brindan una respuesta al Otro a partir de la palabra, los gestos, las acciones o las decisiones.

Para los participantes del presente estudio responder al Otro es un acto inherente en todo aquél que se ha dedicado a ser docente. Es desde la labor del ser maestro y maestra que se atiende al llamado de servicio y se da una respuesta al Otro con total disposición: una respuesta cargada de decisiones por el bienestar, integridad y dignidad del estudiantado. En virtud de ello, se puede concluir que la responsabilidad educativa para el profesorado es una vocación por el Otro. De esta manera, la responsabilidad educativa se origina en el proceso humano de desprendimiento de sí mismo hasta brindar una respuesta ética a la presencia desbordante del Otro.

Por otra parte, cabe mencionar que, en medio del desarrollo de la presente investigación, se elaboró y estableció una ruta metodológica para estudiar e indagar la responsabilidad por el Otro. Es así como la fenomenología de la responsabilidad surge como un método dirigido al Otro y cuyo proceso de investigación reflexivo se logra empleando los existenciales de: la renuncia de sí mismo por el Otro, la preocupación por el Otro, la apertura al Otro, la donación hacia el Otro y la afectación por el Otro.

Dentro de las principales recomendaciones, se considera pertinente ampliar los criterios de selección para incluir profesorado que se hayan dedicado a la educación sin título profesional. Se considera también pertinente ampliar los criterios de selección incluyendo docentes que se dediquen a la educación no formal. Por último, se recomienda a futuros investigadores aplicar la fenomenología de la responsabilidad a fin de indagar cómo se vivencia la responsabilidad por el Otro en distintos agentes educativos como las familias, las amistades, los medios de comunicación, el estado entre otros.

\section{REFERENCIAS}

Aguirre, J.C. y Jaramillo, J.G. (2006). El otro en Lévinas: Una salida a la encrucijada sujeto-objeto y su pertinencia en las ciencias sociales. Revista Latinoamericana de Ciencias Sociales, Niñez y Juventud, 4(2), 3-18.

Alliaud, A. y Antelo, E. (2011). Los gajes del oficio. Enseñanza, pedagogía y formación. Buenos Aires: EIQUE Educación

Antelo, E. (2009). ¿Qué tipo de compromiso es el compromiso docente? En Conferencia del Congreso Educativo y Popular A.D.O.S.A.C. (Asociación de docente de Santa Cruz). Conferencia llevada a cabo en Río Gallegos, Argentina. Recuperado de http://www.estanislaoantelo.com.ar/files/compromisodocente_v2.pdf

Bárcena, F. (2005). La Experiencia Reflexiva en Educación. Barcelona: PAIDO IBERICA

Bárcena, F. (2012). El aprendiz eterno: Filosofia, Educación y el Arte de Vivir. Buenos Aires: Miño y Dávila Ediciones

Bárcena, F. (2016). En Busca de una Educación Pérdida. Barcelona: Homo Sapiens Ediciones

Casanova, E.M. (1991). Para comprender las ciencias de la educación. Pamplona: Verbo Divino

Cuelí, J. (1985). Vocación y afectos. Ciudad de México: Limusa

Duch, L. (2002). Antropología de la vida cotidiana. Argentina: Trotta 
De la Cuesta, C. (2006). Estrategias cualitativas más usadas en el campo de la salud. Revista Nure Investigación, (25), 1-4 D’Egremy, A.F. (1982). Cómo descubrir tú vocación. Ciudad de México: Editorial Anaya

Corts, I. (2002). Educar: un arte, una ciencia... una vocación. Revista Escuela Abierta, 5, 91-98

Fernández T.G. y Sarmiento, F. (2014). ¿Qué hay detrás de la profesión de educar? Un amor a la vida. Revista Nodos y Nudos, 4(36), 117-122 https://doi.org/10.17227/01224328.3117

Freire, P. (2008). Pedagogía del Oprimido. Buenos Aires: Siglo XXI Editores

Gaja, R. (2016). Bienestar, Autoestima y Felicidad. España: De Bolsillo

Gusdorf, G. (1980).¿Para qué los profesores? Paris: P.U.F.

Heidegger, M. (2010). El ser y el tiempo. México: Fondo de Cultura Económico.

Hernández, R., Fernández, C y Baptista, P. (2010). Metodología de la investigación. México: McGrawHill Educación Isaacs, D. (2002). La educación de las virtudes humanas y su evaluación. España: EUNSA

Jaramillo, L.G. (2017). Escuela y donación. De la mano del Dicho... al oído del decir. En D.A. Jaramillo y J.F. Orrego (Comps). Cuadernos de Educación y Alteridad 1 Ética y Responsabilidad en las Humanidades (pp 145-157). Manizales: Matiz Taller Editorial

Kornblit, A. (2004). Metodologias cualitativas en ciencias sociales. Modelos y procedimientos de análisis. Buenos Aires: Biblos.

Lamprea, P.A. y Pineda, A.Y. (2017). Sentidos de alteridad en los docentes de educación media. (Tesis de Maestría). Universidad de Manizales, Colombia. Recuperado de https://bit.ly/2qzd46W

Lévinas, E. (1991), Humanismo del otro hombre. Madrid: Visor

Lévinas, E. (2012). Totalidad e Infinito. Salamanca: EDICIONES SÍGUEME

Lévinas, E. (2014). Alteridad y trascendencia. España: Arena Libros

Martínez, E. (2009). Buscando el sentido de la vida. Bogotá: Aquí y Ahora.

Maturana, H. (1996) El sentido de lo humano. Santiago de Chile: Ediciones Dolmen

Meirieu. P. (2006). Cartas a un joven profesor. Por qué enseñar hoy. Barcelona: GRAO

Mèlich, J.C. (2014). Lógica de la crueldad. Barcelona: HERDER Editorial

Monje, C.A. (2011). Metodología de la investigación cualitativa. Guia didáctica. (Tesis). Universidad Surcolombiana, Neiva - Colombia. Recuperado de https://bit.ly/35IFeuY

Mounier, E. (2000). El personalismo. Madrid: Editorial El Búho

Orrego, J.F. y Portela. H. (2009). Sentido de la alteridad en la formación del licenciado en Educación Física. Revista Educación Fisica y Deporte, 28(2), 49-57.

Ortega, P. (2014). Educar en la alteridad. Madrid: Editorial REDIPE

Pantoja, C. (1992). En torno al concepto de vocación. Educación y Ciencia, 2(6), 17-20

Parra, A.M. y Vallejo, C.S. (2013). Las prácticas pedagógicas en la básica primaria: un espacio para reconocer al otro. (Tesis de Maestría). Universidad de Manizales, Colombia. Recuperado de http://ridum.umanizales.edu.co:808 0/xmlui/handle/6789/1252

Porta, L.G y Flores, G.N. (2017) La hospitalidad en profesores memorables universitarios. Revista de Estudios y Experiencias en Educación, 16(30),15-31 https://doi.org/10.21703/rexe.20173015311

Portilla, M., Rojas, A. y Hernández, I. (2014). Investigación cualitativa: una reflexión desde la educación como hecho social. Revista Docencia, Investigación, Innovación. 3(2), 86-100.

Romero, E. y Pérez, C. (2012). Aproximación al concepto de responsabilidad en Lévinas: implicaciones educativas. Bordón, 64(4), 99-110

Romero, E. y Gutiérrez, M. (2011). La idea de responsabilidad en Lévinas: implicaciones educativas. En Memoria XII Congreso Internacional de Teoría de la Educación. Conferencia llevada a cabo en el Seminario Interuniversitario de Teoría de la Educación (SITE), Universidad de Barcelona, Barcelona, España. Recuperado de: http://www. cite2011.com/Comunicaciones/A+R/139.pdf 
Tany Giselle Fernández Guayana. Fenomenología de la responsabilidad por el Otro: un estudio sobre ...

Skliar, C. (2005). La intimidad y la alteridad. Buenos Aires: Miño y Dávila Editores

Skliar, C. (2007). La Educación (que es) del Otro. Buenos Aires: NOVEDUC

Skliar, C. y Tellez M. (2008). Conmover la Educación. Ensayos para una pedagogía de la diferencia. Buenos Aires: NOVEDUC

Van Manen, M. (2016). Fenomenología de la práctica. Método de donación de sentido en la investigación y la escritura fenomenológica. Colombia: Editorial Universidad del Cauca UC

Zambrano, M. (1965). Filosofía y Educación. Manuscritos. Editorial ECU

CC BY-NC-ND 